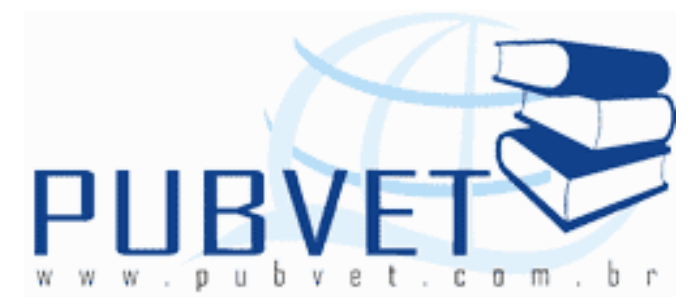

PUBVET, Publicações em Medicina Veterinária e Zootecnia.

\title{
Características de carcaça e do trato digestório de frangos alimentados com batata doce e enzimas
}

\footnotetext{
Juliana Klug Nunes ${ }^{1 *}$, Fabiane Pereira Gentilini ${ }^{2}$, João Pedro Zabaleta ${ }^{3}$, Fernanda Medeiros Gonçalves ${ }^{1}$, Marcos Antonio Anciuti ${ }^{2}$; Fernando Rutz ${ }^{4}$, João Carlos Maier ${ }^{5}$
}

${ }^{1}$ Médica Veterinária, D.Sc., Universidade Federal de Pelotas/UFPel, Campus Universitário s/n, 96010-900, Capão do Leão/RS, Brasil.

${ }^{2}$ Médico Veterinário, D.Sc. Prof. Instituto Federal Sul-Rio-grandense, Campus Visconde da Graça (CaVG), Pelotas/RS, Brasil.

3 Engenheiro Agrônomo, Pesquisador, Embrapa Suínos e Aves, Pelotas/RS, Brasil.

${ }^{4}$ Médico Veterinário, Ph.D., Prof. UFPel, Pelotas/RS, Brasil.

${ }^{5}$ Engenheiro Agrônomo, D.Sc., Prof. UFPel, Pelotas/RS, Brasil.

*Autor para Correspondência. E-mail: julianaklug@yahoo.com.br

\section{Resumo}

O estudo objetivou avaliar características de carcaça, alometria de órgãos e biometria intestinal de frangos de corte alimentados com farinha de batata doce com ou sem suplementação de um complexo enzimático. Cento e cinquenta pintos machos, com um dia de idade foram distribuídos em boxes de duas baterias metálicas. O delineamento experimental utilizado foi o de blocos ao acaso em arranjo fatorial $3 \times 2$ (3 níveis de farinha de batata doce $(0,20$ e 
40\%) e 2 níveis do complexo enzimático ( 0 e $200 \mathrm{~g} /$ ton)). O complexo enzimático consistia de fitase, protease, xilanase, ß-glucanase, celulase, amilase e pectinase. Foram utilizados cinco repetições por tratamento e cinco aves por unidade experimental. Após os 28 dias de idade, as aves segundo o tratamento foram realojadas em seis boxes com cama de maravalha. As variáveis foram submetidas à análise da variância e regressão polinomial $(5 \%)$. Os resultados indicam que a substituição do milho pela farinha de batata doce com ou sem a suplementação do complexo enzimático, não demonstrou ser efetiva sobre as características de carcaça e do trato digestório de frangos de corte.

Palavras-chave: alimento, alometria, aves, biometria, Ipomoea batatas, rendimento.

\title{
Carcass and digestive tract traits of broilers fed sweet potato meal and enzymes
}

\begin{abstract}
This study aimed to evaluate carcass traits, organ allometry and intestinal biometry of broilers fed diets containing sweet potato meal with or without supplementation of an enzyme complex. A total of 150 day-old male broiler chicks were distributed in pens of two metallic batteries. The experimental design was a randomized block design in a factorial arrangement $3 \times 2$ (3 levels of sweet potato meal $(0,20$ and $40 \%)$ and 2 levels of enzyme complex $(0$ and $200 \mathrm{~g} /$ ton $)$ ). The enzyme complex consisted of phytase, protease, xilanase, B-glucanase, cellulase, amilase ande pectinase. A total of 5 replicates per treatment and 5 birds per experimental unit were used. After 28 days of age, birds were reallocated on 6 floor pens. Variables were subjected to analysis of variance and polynomial regression analysis (5\%). The results indicate that the replacement of corn by sweet potato meal, with or without enzyme, has shown no effect on carcass and digestive tract traits of broilers.
\end{abstract}

Keywords: ingredients, allometry, birds, biometry, Ipomoea batatas, yield 


\section{INTRODUÇÃO}

A criação avícola se destaca, na economia brasileira, pelo fornecimento de proteína animal de alta qualidade. Considerando que a alimentação representa a maior parcela dos custos de produção e que a criação avícola é vulnerável às oscilações do mercado das matérias-primas, os pesquisadores buscam alimentos alternativos que possam vir a substituir parcial ou totalmente o milho na formulação das dietas dos não ruminantes. Entre os alimentos estudados estão o farelo de arroz integral (BONATO et al., 2004; VIEIRA et al., 2007), o sorgo (GARCIA et al., 2005; PIMENTEL et al., 2007), a quirera de arroz (BRUM JR., et al., 2007) e os subprodutos da mandioca (CAMPELLO et al., 2009).

Outro alimento com potencial e disponibilidade para ser utilizado na alimentação das aves é a batata doce, porém há necessidade de pesquisas e publicações que comprovem a sua eficiência na nutrição animal. De acordo com Rostagno et al. (2005), a farinha da batata doce ao ser comparada com o milho apresenta maior teor de fibras e de cinzas e equivalente conteúdo de amido.

Associado ao estudo de alimentos alternativos, na nutrição de aves, está o das enzimas exógenas, pois os pesquisadores buscam a remoção ou destruição de fatores antinutricionais presentes em cereais e em seus respectivos subprodutos, o aumento da digestibilidade e o aproveitamento de ingredientes, a potencialização da ação das enzimas endógenas e a diminuição da poluição ambiental causada por alguns nutrientes (fósforo, nitrogênio, cobre, zinco) excretados nas fezes dos animais, ou seja, buscam atuação das enzimas exógenas suplementadas nas dietas dos não ruminantes (COSTA et al., 2004).

Com o propósito de avaliar características de carcaça, alometria de órgãos e biometria intestinal de frangos de corte alimentados com diferentes níveis de farinha de batata doce em substituição ao milho com ou sem suplementação de um complexo enzimático realizou-se a pesquisa. 


\section{MATERIAL E MÉTODOS}

O estudo foi realizado no aviário de frangos de corte do Departamento de Zootecnia, da Universidade Federal de Pelotas/UFPel. Durante 28 dias, 150 pintos Cobb, machos, de um dia de idade, foram criados em 30 boxes de duas baterias metálicas. As aves dispuseram de $20 \mathrm{~cm}$ de espaço de comedouro do tipo calha e tinham acesso a um bebedouro do tipo copo.

Por envolver animais, o projeto de pesquisa foi submetido à Comissão de Ética e Experimentação Animal (CEEA) da instituição de ensino (UFPel) e está protocolado sob número 85.

A temperatura média do aviário foi de $26,8^{\circ} \mathrm{C}$ e a umidade média relativa do ar de 66,34\%, sendo registradas por um termo-higrômetro. A iluminação foi feita por lâmpadas incandescentes de $60 \mathrm{~W}$ e o programa de luz foi controlado por relógio timer. O fornecimento e a intensidade de luz diária seguiram as orientações do guia de manejo da linhagem Cobb.

Antes de iniciar o experimento, as aves foram pesadas individualmente e divididas em cinco grupos de 30 com pesos corporais médios de 39,6; 41,0; 45,$2 ; 47,8$ e 49,2 g e os 30 boxes foram classificados em cinco grupos de seis boxes homogêneos quanto às características do ambiente. Após, cada grupo de aves foi alocado a um grupo de boxes, formando cinco blocos cada um com seis unidades experimentais (boxe com cinco aves). Por fim, os seis tratamentos foram assinalados aleatoriamente aos seis boxes de cada bloco, o que originou cinco repetições por tratamento.

Portanto, o delineamento experimental foi o de blocos ao acaso em arranjo fatorial $3 \times 2$, ou seja, os tratamentos utilizados foram às combinações dos três níveis (0, 20 e 40\%) de farinha de batata doce (Ipomoea batatas) em substituição ao milho e dos dois níveis ( 0 e $200 \mathrm{~g} /$ ton) do complexo enzimático (Tabelas 1,2 e 3 ). 
NUNES, J.K. et al. Características de carcaça e do trato digestório de frangos alimentados com batata doce e enzimas. PUBVET, Londrina, V. 7, N. 11, Ed. 234, Art. 1546, 2013.

Tabela 1. Composição das dietas pré-inicial ( 1 a 7 dias de idade) e inicial ( 8 a 14 dias de idade) fornecidas aos frangos de corte, durante o período experimental

\begin{tabular}{|c|c|c|c|c|c|c|c|c|c|c|}
\hline \multirow[b]{2}{*}{ Ingrediente (\%) } & \multicolumn{4}{|c|}{ Pré-inicial } & \multicolumn{6}{|c|}{ Inicial } \\
\hline & $\mathrm{T}_{1}$ & $T_{2}, T_{3}$ & $\mathrm{~T}_{4}$ & $T_{5}, T_{6}$ & $\mathrm{~T}_{1}$ & $\mathrm{~T}_{2}$ & $T_{3}$ & $\mathrm{~T}_{4}$ & $\mathrm{~T}_{5}$ & $\mathrm{~T}_{6}$ \\
\hline Milho & 55,53 & 32,70 & 55,53 & 32,70 & 59,53 & 35,82 & 10,90 & 59,53 & 35,82 & 10,90 \\
\hline Farelo de soja & 38,10 & 38,52 & 38,10 & 38,52 & 33,90 & 35,60 & 37,75 & 33,90 & 35,60 & 37,75 \\
\hline Farelo de trigo & 0,00 & 0,00 & 0,00 & 0,00 & 0,00 & 0,00 & 0,00 & 0,00 & 0,00 & 0,00 \\
\hline $\begin{array}{l}\text { Farinha de batata } \\
\text { doce }\end{array}$ & 0,00 & 20,00 & 0,00 & 20,00 & 0,00 & 20,00 & 40,00 & 0,00 & 20,00 & 40,00 \\
\hline Farinha de ostra fina & 0,52 & 0,49 & 0,52 & 0,49 & 0,47 & 0,42 & 0,38 & 0,47 & 0,42 & 0,38 \\
\hline Sal iodado & 0,68 & 0,62 & 0,68 & 0,62 & 0,43 & 0,36 & 0,30 & 0,43 & 0,36 & 0,30 \\
\hline Óleo de soja & 2,17 & 4,67 & 2,17 & 4,67 & 2,67 & 4,80 & 7,67 & 2,67 & 4,80 & 7,67 \\
\hline Suplemento ${ }^{1}$ & 3,00 & 3,00 & 3,00 & 3,00 & 3,00 & 3,00 & 3,00 & 3,00 & 3,00 & 3,00 \\
\hline $\begin{array}{l}\text { Complexo enzimático } \\
2\end{array}$ & 0,00 & 0,00 & 0,02 & 0,02 & 0,00 & 0,00 & 0,00 & 0,02 & 0,02 & 0,02 \\
\hline Total & 100,00 & 100,00 & 100,00 & 100,00 & 100,00 & 100,00 & 100,00 & 100,00 & 100,00 & 100,00 \\
\hline EM (kcal/kg) & 2.950 & 2.950 & 2.950 & 2.950 & 3.000 & 3.000 & 3.000 & 3.000 & 3.000 & 3.000 \\
\hline Proteína bruta (\%) & 21,735 & 21,065 & 21,735 & 21,000 & 20,000 & 20,000 & 20,000 & 20,000 & 20,000 & 20,000 \\
\hline Fibra bruta (\%) & 3,798 & 4,009 & 3,798 & 4,001 & 3,679 & 3,873 & 4,167 & 3,679 & 3,873 & 4,167 \\
\hline Lipídeos totais (\%) & 4,776 & 6,590 & 4,776 & 6,561 & 4,671 & 6,797 & 8,925 & 4,671 & 6,797 & 8,925 \\
\hline $\begin{array}{l}\text { Aminoácidos totais } \\
(\%)\end{array}$ & 0,577 & 0,820 & 0,577 & 0,819 & 0,833 & 0,793 & 0,753 & 0,833 & 0,793 & 0,753 \\
\hline Metionina total (\%) & 0,519 & 0,485 & 0,519 & 0,484 & 0,497 & 0,472 & 0,447 & 0,497 & 0,472 & 0,447 \\
\hline Lisina total (\%) & 1,260 & 1,225 & 1,260 & 1,220 & 1,135 & 1,148 & 1,162 & 1,135 & 1,148 & 1,162 \\
\hline Cálcio (\%) & 1,000 & 1,000 & 1,000 & 1,000 & 0,970 & 0,970 & 0,970 & 0,970 & 0,970 & 0,970 \\
\hline Fósforo disponível (\%) & 0,460 & 0,456 & 0,460 & 0,456 & 0,452 & 0,451 & 0,450 & 0,452 & 0,451 & 0,450 \\
\hline Sódio total (\%) & 0,300 & 0,300 & 0,300 & 0,301 & 0,201 & 0,200 & 0,201 & 0,201 & 0,200 & 0,201 \\
\hline
\end{tabular}

Níveis de garantia por $\mathrm{kg}$ do produto: ${ }^{1}$ Suplemento mineral, vitamínico e aminoácidos - Núcleo: vitamina A: 240.000 UI, vitamina $D_{3}: 53.000 \mathrm{UI}$, vitamina $\mathrm{E}: 433 \mathrm{mg}$, vitamina $\mathrm{K}_{3}: 580 \mathrm{mg}$, vitamina $B_{1}: 60 \mathrm{mg}$, vitamina $B_{2}: 170 \mathrm{mg}$, vitamina $B_{6}$ : $100 \mathrm{mg}$, vitamina $\mathrm{B}_{12}: 400 \mathrm{mcg}$, niacina: $1.160 \mathrm{mg}$, ácido pantotênico: $400 \mathrm{mg}$, ácido fólico: $25 \mathrm{mg}$; cálcio: $266 \mathrm{~g}$, fósforo $102 \mathrm{~g}$, flúor: $710 \mathrm{mg}$, manganês: $3.334 \mathrm{mg}$, zinco: $2.000 \mathrm{mg}$; ferro: $1.667 \mathrm{mg}$, cobre: $333 \mathrm{mg}$, iodo: $20 \mathrm{mg}$, selênio: 11 mg, metionina: $40 \mathrm{~g}$.

${ }^{2}$ Complexo enzimático: fitase, protease, xilanase, B-glucanase, celulase, amilase e pectinase. 
NUNES, J.K. et al. Características de carcaça e do trato digestório de frangos alimentados com batata doce e enzimas. PUBVET, Londrina, V. 7, N. 11, Ed. 234, Art. 1546, 2013.

Tabela 2. Composição das dietas de crescimento ( 15 a 28 dias de idade) fornecidas aos frangos de corte, durante o período experimental

\begin{tabular}{|c|c|c|c|c|c|c|}
\hline Ingrediente (\%) & $T_{1}$ & $\mathrm{~T}_{2}$ & $T_{3}$ & $\mathrm{~T}_{4}$ & $T_{5}$ & $T_{6}$ \\
\hline Milho & 60,78 & 38,27 & 13,32 & 60,78 & 38,27 & 13,32 \\
\hline Farelo de soja & 32,80 & 33,00 & 35,20 & 32,80 & 33,00 & 35,20 \\
\hline Farinha de batata doce & 0,00 & 20,00 & 40,00 & 0,00 & 20,00 & 40,00 \\
\hline Farinha de ostra fina & 0,34 & 0,26 & 0,22 & 0,34 & 0,26 & 0,22 \\
\hline Sal iodado & 0,38 & 0,32 & 0,25 & 0,38 & 0,32 & 0,25 \\
\hline Óleo de soja & 2,70 & 5,15 & 8,01 & 2,70 & 5,15 & 8,01 \\
\hline Suplemento ${ }^{1}$ & 3,00 & 3,00 & 3,00 & 3,00 & 3,00 & 3,00 \\
\hline Complexo enzimático ${ }^{2}$ & 0,00 & 0,00 & 0,00 & 0,02 & 0,00 & 0,02 \\
\hline Total & 100,00 & 100,00 & 100,00 & 100,00 & 100,00 & 100,00 \\
\hline \multicolumn{7}{|l|}{ Composição calculada } \\
\hline \multicolumn{7}{|l|}{ Energia metabolizável } \\
\hline Proteína bruta (\%) & 19,702 & 19,000 & 19,000 & 19,702 & 19,000 & 19,000 \\
\hline Fibra bruta (\%) & 3,540 & 3,748 & 4,043 & 3,540 & 3,748 & 4,043 \\
\hline Lipídeos totais (\%) & 5,416 & 7,180 & 9,313 & 5,416 & 7,180 & 9,313 \\
\hline Aminoácidos totais (\%) & 0,780 & 0,722 & 0,682 & 0,780 & 0,722 & 0,682 \\
\hline Metionina total (\%) & 0,448 & 0,414 & 0,389 & 0,448 & 0,414 & 0,389 \\
\hline Lisina total (\%) & 1,100 & 1,062 & 1,076 & 1,100 & 1,062 & 1,076 \\
\hline Cálcio (\%) & 0,967 & 0,950 & 0,950 & 0,967 & 0,950 & 0,950 \\
\hline Fósforo disponível (\%) & 0,415 & 0,410 & 0,409 & 0,415 & 0,410 & 0,409 \\
\hline Sódio total (\%) & 0,180 & 0,182 & 0,180 & 0,180 & 0,182 & 0,180 \\
\hline \multicolumn{7}{|c|}{$\begin{array}{l}\text { Níveis de garantia por } \mathrm{kg} \text { do produto: }{ }^{1} \text { Suplemento mineral, vitamínico e } \\
\text { aminoácidos - Núcleo: vitamina } \mathrm{A}: 240.000 \mathrm{UI} \text {, vitamina } \mathrm{D}_{3}: 53.000 \text { UI, vitamina E: } \\
433 \mathrm{mg} \text {, vitamina } \mathrm{K}_{3}: 580 \mathrm{mg} \text {, vitamina } \mathrm{B}_{1}: 60 \mathrm{mg} \text {, vitamina } \mathrm{B}_{2}: 170 \mathrm{mg} \text {, vitamina } \\
\mathrm{B}_{6}: 100 \mathrm{mg} \text {, vitamina } \mathrm{B}_{12}: 400 \mathrm{mcg} \text {, niacina: } 1.160 \mathrm{mg} \text {, ácido pantotênico: } 400 \mathrm{mg} \text {, } \\
\text { ácido fólico: } 25 \mathrm{mg} \text {; cálcio: } 266 \mathrm{~g} \text {, fósforo } 102 \mathrm{~g} \text {, flúor: } 710 \mathrm{mg} \text {, manganês: } 3.334 \\
\mathrm{mg} \text {, zinco: } 2.000 \mathrm{mg} \text {; ferro: } 1.667 \mathrm{mg} \text {, cobre: } 333 \mathrm{mg} \text {, iodo: } 20 \mathrm{mg} \text {, selênio: } 11 \\
\mathrm{mg} \text { metionina: } 40 \mathrm{~g} \text {. } \\
2 \text { Complexo enzimático: fitase, protease, xilanase, B-glucanase, celulase, amilase e } \\
\text { pectinase. }\end{array}$} \\
\hline
\end{tabular}


NUNES, J.K. et al. Características de carcaça e do trato digestório de frangos alimentados com batata doce e enzimas. PUBVET, Londrina, V. 7, N. 11, Ed. 234, Art. 1546, 2013.

Tabela 3. Composição das dietas finais (35 a 47 dias de idade) fornecidas aos frangos de corte durante o período experimental

\begin{tabular}{lcccccc}
\hline Ingrediente (\%) & $\mathrm{T}_{1}$ & $\mathrm{~T}_{2}$ & $\mathrm{~T}_{3}$ & $\mathrm{~T}_{4}$ & $\mathrm{~T}_{5}$ & $\mathrm{~T}_{6}$ \\
\hline Milho & 65,86 & 40,72 & 15,70 & 65,86 & 40,72 & 15,70 \\
Farelo de soja & 28,20 & 30,50 & 32,70 & 28,20 & 30,50 & 32,70 \\
Farinha de batata doce & 0,00 & 20,00 & 40,00 & 0,00 & 20,00 & 40,00 \\
Farinha de ostra fina & 0,00 & 0,00 & 0,00 & 0,00 & 0,00 & 0,00 \\
Sal iodado & 0,38 & 0,32 & 0,25 & 0,38 & 0,32 & 0,25 \\
Óleo de soja & 2,56 & 5,46 & 8,35 & 2,56 & 5,46 & 8,35 \\
Suplemento & 3,00 & 3,00 & 3,00 & 3,00 & 3,00 & 3,00 \\
Complexo enzimático ${ }^{2}$ & 0,00 & 0,00 & 0,00 & 0,02 & 0,02 & 0,02 \\
\hline Total & 100,00 & 100,00 & 100,00 & 100,00 & 100,00 & 100,00 \\
\hline Composição calculada & & & & & & \\
\hline Energia metabolizável & & & & & & \\
(kcal/kg) & 3.100 & 3.100 & 3.100 & 3.100 & 3.100 & 3.100 \\
Proteína bruta (\%) & 18,000 & 18,000 & 18,000 & 18,000 & 18,000 & 18,000 \\
Fibra bruta (\%) & 3,330 & 3,624 & 3,917 & 3,330 & 3,624 & 3,917 \\
Lipídeos totais (\%) & 5,396 & 7,552 & 9,704 & 5,396 & 7,552 & 9,704 \\
Aminoácidos totais (\%) & 0,664 & 0,624 & 0,583 & 0,664 & 0,624 & 0,583 \\
Metionina total (\%) & 0,368 & 0,328 & 0,303 & 0,368 & 0,328 & 0,303 \\
Lisina total (\%) & 0,980 & 0,994 & 1,008 & 0,980 & 0,994 & 1,008 \\
Cálcio (\%) & 0,916 & 0,931 & 0,947 & 0,916 & 0,931 & 0,947 \\
Fósforo disponível (\%) & 0,384 & 0,383 & 0,382 & 0,384 & 0,383 & 0,382 \\
Sódio total (\%) & 0,180 & 0,181 & 0,180 & 0,180 & 0,181 & 0,180 \\
\hline
\end{tabular}

Níveis de garantia por $\mathrm{kg}$ do produto: ${ }^{1}$ Suplemento mineral, vitamínico e aminoácidos - Núcleo: vitamina $A$ : 240.000 UI, vitamina $D_{3}: 53.000$ UI, vitamina E: $433 \mathrm{mg}$, vitamina $\mathrm{K}_{3}: 580 \mathrm{mg}$, vitamina $B_{1}: 60 \mathrm{mg}$, vitamina $B_{2}: 170 \mathrm{mg}$, vitamina $\mathrm{B}_{6}: 100 \mathrm{mg}$, vitamina $\mathrm{B}_{12}: 400 \mathrm{mcg}$, niacina: $1.160 \mathrm{mg}$, ácido pantotênico: $400 \mathrm{mg}$, ácido fólico: $25 \mathrm{mg}$; cálcio: $266 \mathrm{~g}$, fósforo $102 \mathrm{~g}$, flúor: $710 \mathrm{mg}$, manganês: 3.334 mg, zinco: $2.000 \mathrm{mg}$; ferro: $1.667 \mathrm{mg}$, cobre: $333 \mathrm{mg}$, iodo: $20 \mathrm{mg}$, selênio: 11 $\mathrm{mg}$, metionina: $40 \mathrm{~g}$.

${ }^{2}$ Complexo enzimático: fitase, protease, xilanase, ß-glucanase, celulase, amilase e pectinase.

O complexo enzimático composto por fitase, protease, xilanase, Bglucanase, celulase, amilase e pectinase e obtido a partir do fungo Aspergillus niger foi adicionado às dietas de forma on top. Já a farinha de batata doce empregada era proveniente de lavouras de agricultura familiar do município de Mariana Pimentel/RS. A farinha de batata doce utilizada apresentava na sua composição $88,72 \%$ de matéria seca, 4,56\% de proteína bruta, $4,96 \%$ de fibra bruta, $1,58 \%$ de cinzas e $3.450 \mathrm{kcal} / \mathrm{kg}$ de energia bruta.

Para a adoção do programa alimentar considerou-se a idade das aves, dividindo-o em fase pré-inicial: 1 a 7 dias, inicial: 8 a 14 dias, de 
crescimento: 15 a 34 dias, e final: 35 a 47 dias. Tanto as rações na forma farelada como a água foram fornecidas à vontade.

Ao término dos 28 dias de idade, os frangos de corte foram transferidos, de acordo com o tratamento, para seis boxes com cama de maravalha.

As avaliações experimentais foram procedidas aos 39 e aos 47 dias de idade dos frangos de corte. Assim sendo, em cada um desses dias, três aves por tratamento foram separadas aleatoriamente e pesadas $(\mathrm{g})$. Após um jejum de seis horas, os frangos de corte foram pesados ( $\mathrm{g}$ ) novamente e, em seguida processados, segundo os procedimentos normais de abate: atordoamento, sangria, depenagem e evisceração.

As carcaças com pés, sem cabeça, vísceras comestíveis e gordura abdominal foram pesadas $(\mathrm{g})$ após o resfriamento no chiller e gotejamento. Em seguida, procedeu-se à extração do peito sem pele, coxas e sobrecoxas, asas, coxas das asas, dorso com pescoço e patas. Estes cortes foram pesados ( $\mathrm{g}$ ) e o rendimento de carcaça foi calculado em relação ao peso vivo após o jejum [Rendimento de carcaça $(\%)=($ Peso Carcaça $\times 100) /$ Peso Vivo] e o rendimento dos cortes em relação ao peso da carcaça [Rendimento dos cortes $(\%)=($ Peso Cortes $\times 100) /$ Peso Carcaça $]$.

Para a análise alométrica das vísceras, o coração e o fígado foram pesados ( $\mathrm{g}$ ) após a retirada, enquanto que o proventrículo e a moela foram pesados $(\mathrm{g}$ ) em balança digital após a remoção dos seus conteúdos. Já para a análise biométrica, o comprimento $(\mathrm{cm})$ dos intestinos (duodeno, jejuno, íleo, cólon-reto e cecos) foi obtido em local apropriado e com a utilização de uma fita métrica.

Os dados coletados foram submetidos à análise de variância para os testes de significâncias dos efeitos principais e da interação de farinha de batata doce e complexo enzimático, seguida da decomposição da variação entre os níveis do fator farinha de batata doce em componentes polinomiais. As decomposições e os ajustamentos de funções de resposta foram procedidos globalmente para os dois níveis de complexo enzimático ou 
separadamente para cada um desses níveis, respectivamente nas situações de ausência ou presença de significância da interação farinha de batata doce e complexo enzimático. Foi adotada a probabilidade de $5 \%$ para aceitação ou rejeição da hipótese de nulidade.

As análises foram fundamentadas no modelo estatístico onde o valor observado da variável resposta na unidade experimental com a combinação do nível $i$ do fator farinha de batata doce com o nível $j$ do fator complexo enzimático no bloco $k$ foi expresso pela equação: $Y_{i j k}=m+a_{i}+b_{j}+a b_{i j}+$ $\rho_{k}+e_{i j k}, i=1,2,3 ; j=1,2 ; k=1,2,3,4,5$, onde: $m$ : média geral, $a_{i}$ : efeito do nível $i$ da farinha de batata doce, $b_{j}$ : efeito do nível $j$ do complexo enzimático, $a b_{i j}$ : efeito da interação dos níveis $i$ e $j$ desses dois fatores experimentais, $\rho_{k}$ : efeito do bloco $k$ e $e_{i j k}$ : erro experimental. Foram admitidas as pressuposições de que os termos $m, a_{i}, b_{j}$ e $a b_{i j}$ são efeitos fixos, e $\rho_{k}$ e $e_{i j k}$ são efeitos aleatórios não correlacionados, com distribuições normais e variâncias homogêneas.

\section{RESULTADOS E DISCUSSÃO}

Para os frangos de corte abatidos aos 39 dias de idade, verificou-se que a interação farinha de batata doce (FBD) e complexo enzimático (CE) foi significativa apenas para o rendimento de carcaça com resposta polinomial quadrática. Derivando-se a equação de regressão polinomial obteve-se $6 \%$ como sendo o nível máximo de FBD a ser utilizado para que seja obtido maior rendimento de carcaça das aves (Tabela 4). 
NUNES, J.K. et al. Características de carcaça e do trato digestório de frangos alimentados com batata doce e enzimas. PUBVET, Londrina, V. 7, N. 11, Ed. 234, Art. 1546, 2013.

Tabela 4. Resultados das análises de variação das variáveis referentes ao peso da carcaça e aos rendimentos de carcaça e cortes dos frangos, aos 39 dias de idade, e equações polinomiais ajustadas para expressar as respostas aos níveis de FBD

\begin{tabular}{|c|c|c|c|c|c|c|c|c|c|}
\hline \multirow[b]{2}{*}{ FBD } & \multicolumn{9}{|c|}{ Característica $^{1}$} \\
\hline & PCj & PCar & RCar & CxSobr & Peito & Cxasa & Asa & Dorso & Pata \\
\hline 0 & 2.475 & 1.978 & 79,95 & 27,99 & 32,49 & 4,60 & 4,65 & 22,41 & 4,54 \\
\hline 20 & 2.225 & 1.756 & 78,88 & 27,78 & 30,19 & 4,49 & 4,66 & 23,14 & 4,73 \\
\hline 40 & 2.158 & 1.590 & 74,50 & 29,59 & 30,75 & 3,82 & 4,81 & 22,87 & 4,69 \\
\hline$P^{2}$ & 0,0182 & 0,0431 & 0,0147 & 0,5608 & 0,2473 & 0,2415 & 0,7189 & 0,6767 & 0,8406 \\
\hline \multicolumn{10}{|l|}{ CE } \\
\hline 0 & 2.326 & 1.853 & 79,18 & 28,26 & 31,61 & 4,38 & 4,70 & 22,89 & 4,67 \\
\hline 200 & 2.245 & 1.696 & 76,37 & 28,65 & 30,69 & 4,23 & 4,71 & 22,72 & 4,64 \\
\hline$P^{3}$ & 0,3205 & 0,4386 & 0,1866 & 0,7494 & 0,7561 & 0,9336 & 0,9983 & 0,7884 & 0,8538 \\
\hline \multicolumn{10}{|l|}{ FBD - CE } \\
\hline $0-0$ & 2.525 & 2.012 & 79,70 & 28,60 & 31,59 & 4,77 & 4,57 & 22,56 & 4,64 \\
\hline $20-0$ & 2.195 & 1.736 & 79,05 & 27,86 & 30,87 & 4,24 & 4,71 & 23,21 & 4,73 \\
\hline $40-0$ & 2.260 & 1.812 & 78,78 & 28,33 & 32,36 & 4,13 & 4,81 & 22,89 & 4,63 \\
\hline $0-200$ & 2.424 & 1.944 & 80,19 & 27,38 & 33,40 & 4,42 & 4,73 & 22,26 & 4,45 \\
\hline $20-200$ & 2.256 & 1.776 & 78,71 & 27,70 & 29,51 & 4,74 & 4,60 & 23,06 & 4,74 \\
\hline $40-200$ & 2.056 & 1.368 & 70,23 & 30,86 & 29,15 & 3,51 & 4,82 & 22,85 & 4,74 \\
\hline $\mathrm{P}^{4}$ & 0,4088 & 0,1792 & 0,0075 & 0,3490 & 0,2931 & 0,2495 & 0,7136 & 0,9912 & 0,9248 \\
\hline $\mathrm{CV}(\%)^{5}$ & 7,22 & 8,43 & 1,72 & 5,64 & 6,89 & 10,91 & 5,92 & 6,08 & 11,78 \\
\hline Curva & & . 7 & & & Cte & Cte & Cte & Cte & Cte \\
\hline \multirow{2}{*}{$\mathrm{R}^{29}$} & Lin. ${ }^{\circ}$ & Lin.' & Lin./ Quad. & & CxSobr $=28,20$ & Peito $=31,17$ & Cxasa $=4,43$ & Asa $=4,67$ & Pata $=4,66$ \\
\hline & 0,90 & 0,95 & $0,90 / 0,72$ & 0 & 0 & 0 & 0 & 0 & 0 \\
\hline
\end{tabular}

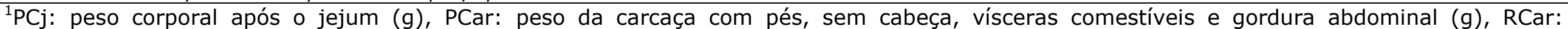

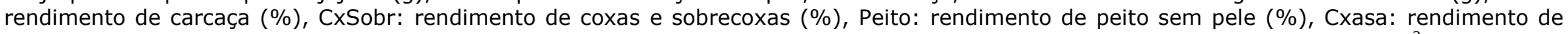

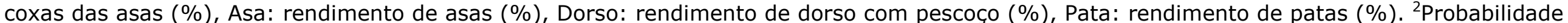

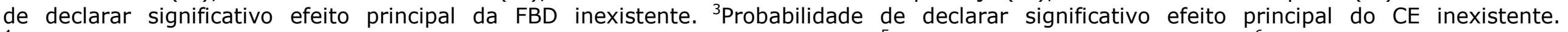

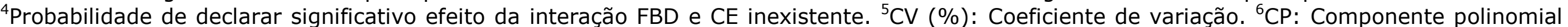

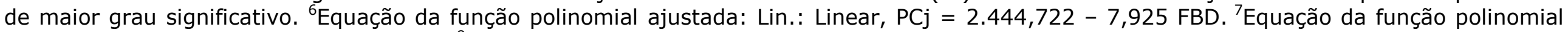

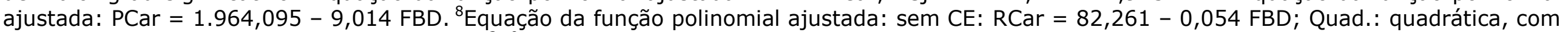
CE: RCar $=80,194+0,120$ FBD $-0,010$ FBD ${ }^{2} .{ }^{9}$ Coeficiente de determinação. 
O efeito principal da FBD influenciou significativamente o peso corporal após o jejum, o peso e o rendimento de carcaça com resposta polinomial linear decrescente. Já para as aves que receberam o CE na dieta, não se constatou efeito significativo para nenhuma das variáveis de carcaça analisadas.

A composição das dietas pré-iniciais (Tabela 1) pode ter influenciado os resultados obtidos, pois é nesta fase que ocorrem alterações morfológicas e fisiológicas de preparo para o aproveitamento de nutrientes da ração.

Contrariando os resultados obtidos Rocha et al. (2008) constataram que a utilização do sorgo em substituição total ao milho pode ser realizada a partir de oito dias de idade dos frangos de corte sem haver interferência negativa nos dados de desempenho e rendimento de carcaça aos 42 dias de idade.

Como os não ruminantes não possuem capacidade enzimática para a digestão de polissacarídeos não amiláceos, a presença destes acarreta aumento da viscosidade do quimo intestinal, diminuição da velocidade de passagem dos alimentos ao longo do trato digestório e dificuldade da ação das enzimas endógenas (BRITO et al. 2008). Provavelmente, o CE foi suplementado em quantidade aquém para a disponibilização dos nutrientes que permaneceram envolvidos pelas fibras e amido resistente presentes nas rações experimentais.

Corroborando com as observações apresentadas (Tabela 4), Bonato et al. (2004) realizaram estudo com frangos de corte, no período de 1 a 42 dias de idade, que receberam rações sem ou com a suplementação enzimática (protease, pentosanase e fitase) e com os níveis de 0, 10, 20 ou $30 \%$ de farelo de arroz integral e observaram menor rendimento de peito, menores pesos da carcaça, do peito e da coxa e concluíram que a utilização do complexo enzimático não proporcionou melhoria nas variáveis estudadas.

Seguindo a linha de pesquisa com alimentos alternativos, Vieira et al. (2007) não observaram efeito significativo da substituição do milho por farelo de arroz integral $(0 ; 3,5 ; 7,5 ; 10,5$ e $14 \%)$ com suplementação de 
fitase sobre pesos da carcaça, peito, coxa e sobrecoxa, asa, dorso, fígado, coração e moela. Campello et al. (2009) ao substituírem milho por farinha de raízes de mandioca $(0,13,36$ e 53\%) na dieta de frangos de corte tipo caipira, verificaram que com o aumento do nível houve redução do peso das aves ao abate (84 dias), sem haver efeito significativo sobre o rendimento de cortes, porém estes autores não observaram efeito significativo dos níveis de farinha de raízes de mandioca sobre o rendimento de carcaça.

Aos 39 dias de idade dos frangos de corte, para os resultados de alometria das vísceras e de biometria dos segmentos intestinais apenas o peso do proventrículo foi influenciado significativamente pela interação FBD e CE. Através da derivação das equações de regressão polinomial obteve-se ponto de mínimo de $18,50 \%$ de FBD sem suplementação do CE e o ponto de máximo de 18,63\% de FBD com suplementação do $C E$, ou seja, nestes percentuais de FBD em substituição ao milho sem ou com suplementação do CE os frangos de corte apresentarão menor e maior peso do proventrículo, respectivamente (Tabela 5 ). 
NUNES, J.K. et al. Características de carcaça e do trato digestório de frangos alimentados com batata doce e enzimas. PUBVET, Londrina, V. 7, N. 11, Ed. 234, Art. 1546, 2013.

Tabela 5. Resultados das análises de variação das variáveis referentes à alometria de órgãos e biometria intestinal dos frangos de corte, aos 39 dias de idade, e equações polinomiais ajustadas para expressar as respostas aos níveis de FBD

\begin{tabular}{|c|c|c|c|c|c|c|c|c|c|}
\hline \multirow[b]{2}{*}{ FBD } & \multicolumn{9}{|c|}{ Característica $^{1}$} \\
\hline & Fig & Cor & Pro & Moe & Duo & Jej & Íleo & Colret & $\mathrm{Cec}$ \\
\hline 0 & 49 & 15 & 9 & 41 & 24 & 98 & 17 & 7 & 16 \\
\hline 20 & 45 & 16 & 10 & 40 & 21 & 96 & 18 & 7 & 16 \\
\hline 40 & 44 & 14 & 8 & 34 & 26 & 114 & 19 & 6 & 18 \\
\hline$P^{2}$ & 0,5094 & 0,4589 & 0,0810 & 0,4836 & 0,0773 & 0,2083 & 0,1901 & 0,4989 & 0,0648 \\
\hline
\end{tabular}

\begin{tabular}{|c|c|c|c|c|c|c|c|c|c|}
\hline CE & & & & & & & & & \\
\hline 0 & 46 & 15 & 9 & 39 & 25 & 99 & 19 & 7 & 18 \\
\hline 200 & 46 & 15 & 8 & 38 & 23 & 106 & 17 & 7 & 15 \\
\hline$P^{3}$ & 0,9187 & 0,8686 & 0,1373 & 0,5886 & 0,2157 & 0,3956 & 0,0133 & 0,8371 & 0,0019 \\
\hline
\end{tabular}

\begin{tabular}{|c|c|c|c|c|c|c|c|c|c|}
\hline $\mathrm{P}^{3}$ & 0,9187 & 0,8686 & 0,1373 & 0,5886 & 0,2157 & 0,3956 & 0,0133 & 0,8371 & 0,0019 \\
\hline \multicolumn{10}{|l|}{ FBD - CE } \\
\hline $0-0$ & 50 & 14 & 9 & 43 & 25 & 93 & 18 & 7 & 17 \\
\hline $20-0$ & 45 & 17 & 9 & 37 & 24 & 86 & 19 & 7 & 17 \\
\hline $40-0$ & 44 & 14 & 10 & 38 & 25 & 117 & 21 & 7 & 20 \\
\hline $0-200$ & 48 & 16 & 8 & 39 & 23 & 102 & 16 & 7 & 14 \\
\hline $20-200$ & 46 & 14 & 11 & 44 & 19 & 106 & 18 & 7 & 16 \\
\hline $40-200$ & 44 & 14 & 7 & 30 & 26 & 111 & 17 & 6 & 16 \\
\hline $\mathrm{P}^{4}$ & 0,9645 & 0,2983 & 0,0176 & 0,0746 & 0,2359 & 0,4684 & 0,5280 & 0,4708 & 0,1856 \\
\hline CV $(\%)^{5}$ & 16,68 & 16,82 & 12,69 & 13,11 & 12,77 & 17,46 & 8,87 & 16,47 & 7,63 \\
\hline $\begin{array}{l}\text { Curva } \\
\mathrm{R}^{211}\end{array}$ & $\begin{array}{c}\text { Cte } \\
\text { Fig }=46 \\
0\end{array}$ & $\begin{array}{l}\operatorname{Lin}^{6} \\
0,95\end{array}$ & $\begin{array}{c}\text { Quad. /Quad. } \\
0,95 / 0,89\end{array}$ & $\begin{array}{l}\text { Lin. }^{8} \\
0,84\end{array}$ & $\begin{array}{c}\text { Quad. }{ }^{9} \\
0,84\end{array}$ & $\begin{array}{c}\text { Cte } \\
\text { Jej }=103 \\
0\end{array}$ & $\begin{array}{c}\text { Cte } \\
\text { Íleo }=18 \\
0\end{array}$ & $\begin{array}{c}\text { Cte } \\
\text { Colret }=7 \\
0\end{array}$ & $\begin{array}{l}\operatorname{Lin}^{1} \\
0,94\end{array}$ \\
\hline & 0 & 0,95 & $0,95 / 0,89$ & 0,84 & 0,84 & 0 & 0 & 0 & 0,94 \\
\hline
\end{tabular}

${ }^{1}$ Fig: peso do fígado (g), Cor: peso do coração (g), Pro: peso do proventrículo (g), Moe: peso da moela (g), Duo: comprimento do duodeno $(\mathrm{cm})$, Jej: comprimento do jejuno $(\mathrm{cm})$, İleo: comprimento do íleo (cm), Colret: comprimento do cólon-reto (cm), Cec: média do comprimento dos cecos $(\mathrm{cm})$.

${ }^{2}$ Probabilidade de declarar significativo efeito principal da FBD inexistente. ${ }^{3}$ Probabilidade de declarar significativo efeito principal do CE inexistente. ${ }^{4}$ Probabilidade de declarar significativo efeito da interação FBD e CE inexistente. ${ }^{5} \mathrm{CV}$ (\%): Coeficiente de variação. ${ }^{6}$ Equação da função polinomial ajustada: Lin.: Linear, Cor $=15,597-0,037$ FBD. ${ }^{7}$ Equação da função polinomial ajustada: Quad.: Quadrática, sem CE: Pro = 9,233 - 0,037 FBD + 0,001 FBD ${ }^{2}$, com CE: Pro = 7,900 + 0,298 FBD - 0,008 FBD ${ }^{2}$; Equação da função polinomial ajustada: Moe $=42,306-0,186$ FBD. ${ }^{9}$ Equação da função polinomial ajustada: Duo = 24,667 - 0,083 FBD + 0,003 FBD 2 . ${ }^{10} \mathrm{Cec}=15,653+0,048$ FBD. ${ }^{11}$ Coeficiente de determinação. 
O efeito principal da FBD não influenciou significativamente nenhuma das variáveis de alometria e biometria avaliadas. Já para as aves que receberam o CE na dieta, constatou-se efeito significativo para o comprimento do íleo e dos cecos com resposta polinomial constante e linear decrescente, respectivamente.

Também se verificou resposta polinomial linear decrescente para o peso do coração e quadrática com ponto de mínimo de 9,22\% para o comprimento do duodeno, o que indicou que as aves que receberam 9,22\% e FBD na dieta apresentaram menor comprimento de duodeno. Takahashi et al. (2006) afirmam que o maior comprimento dos intestinos permite melhor capacidade de absorção de nutrientes, este relato não condiz com o que foi observado no trabalho, pois com o aumento da FBD houve a tendência a aumentar o comprimento dos intestinos e mesmo assim as características de carcaça decresceram (Tabela 4).

Com relação ao peso da moela observou-se resposta polinomial linear decrescente, ou seja, com o aumento da FBD na dieta o peso da moela diminuiu. Este resultado pode ser consequência da granulometria fina da ração que pode ter reduzido a atividade muscular da moela. O observado é coerente com o de Santos et al. (2006), que observaram que, no período de 1 a 21 dias de idade de frangos de corte, o acréscimo do nível de sorgo (0, 50 e $100 \%$ ) em substituição ao milho ocasionou redução no peso relativo da moela. Porém os pesquisadores também verificaram que os tratamentos não interferiram nos pesos de proventrículo, fígado e pâncreas e que para o período de 22 a 42 dias, a suplementação $(0$ e $0,1 \%$ ) de um complexo enzimático (xilanase, amilase e protease) promoveu aumento dos pesos da moela, do proventrículo e do pâncreas. Brum Jr. et al. (2007), aos 42 dias de idade dos frangos de corte, também observaram diminuição linear do rendimento da moela com o aumento da quirera de arroz (0, 20 e 40\%) na dieta.

Aos 47 dias de idade dos frangos de corte, houve efeito da interação FBD e CE sobre o rendimento de coxas e sobrecoxas com resposta 
polinomial linear decrescente, ou seja, com o aumento do nível de FBD na dieta das aves os rendimentos de coxas e sobrecoxas diminuíram. O CE não influenciou o peso corporal após o jejum, o peso da carcaça, os rendimentos de carcaça e dos cortes avaliados. Porém, de forma significativa, o efeito principal da FBD influenciou o peso corporal após o jejum e o peso da carcaça com resposta polinomial linear decrescente e o rendimento de patas com resposta polinomial linear crescente (Tabela 6). 
NUNES, J.K. et al. Características de carcaça e do trato digestório de frangos alimentados com batata doce e enzimas. PUBVET, Londrina, V. 7, N. 11, Ed. 234, Art. 1546, 2013.

Tabela 6. Resultados das análises de variação das variáveis referentes ao peso da carcaça e aos rendimentos de carcaça e cortes dos frangos, aos 47 dias de idade, e equações polinomiais ajustadas para expressar as respostas aos níveis de FBD

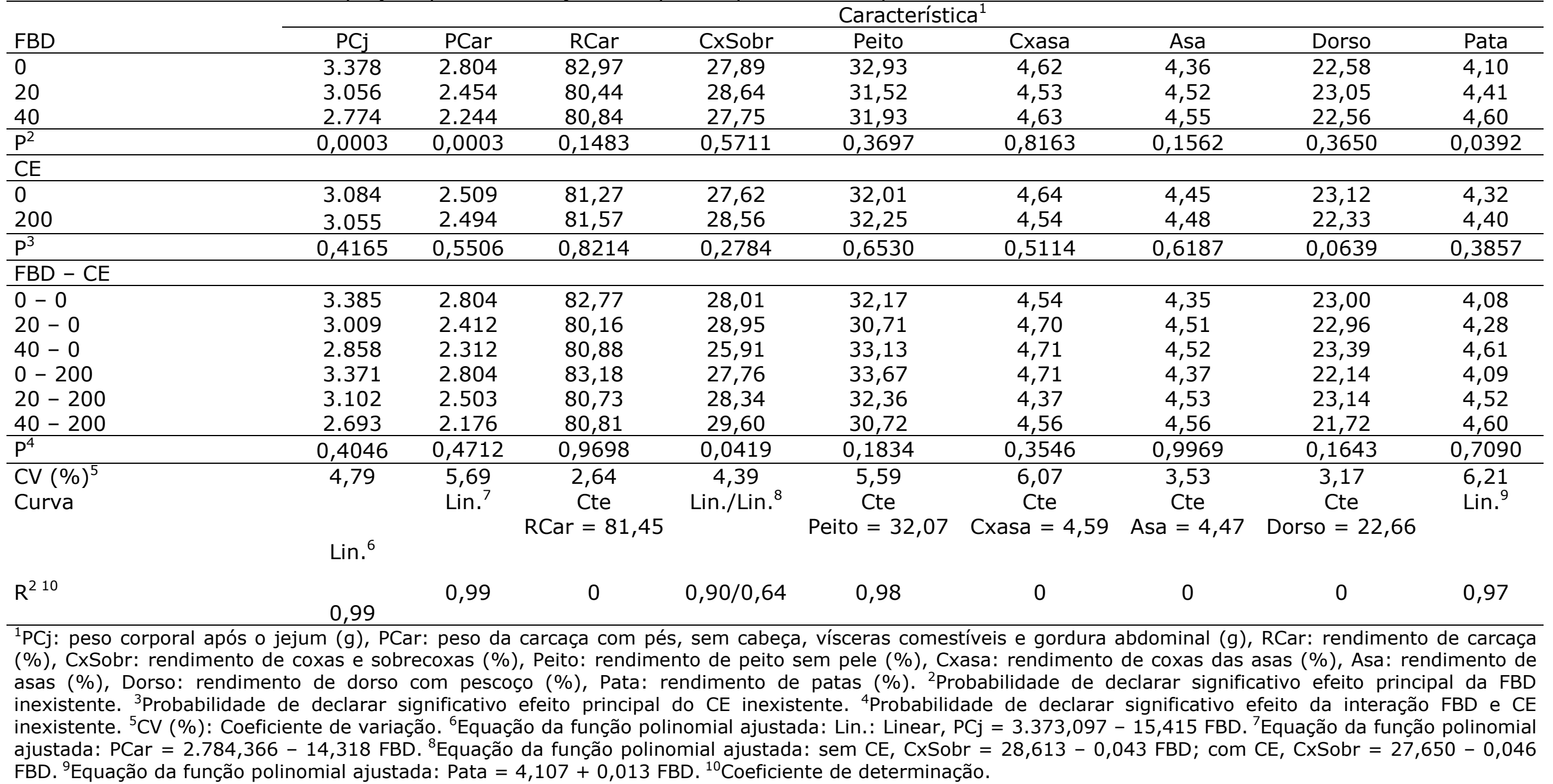


Garcia et al. (2005) utilizaram os níveis de 0, 25, 50, 75 e $100 \%$ de sorgo em substituição ao milho e verificaram que não ocorreu diferenças significativas para peso vivo, rendimento de carcaça, peito, coxa e sobrecoxa, asa e dorso de frangos de corte, aos 42 dias de idade. A redução do peso corporal das aves após o jejum com o aumento do percentual de FBD na dieta diferiu do resultado do autor supracitado.

Os resultados obtidos foram semelhantes aos de Freitas et al. (2008) que ao incluírem níveis $(0 ; 7,5 ; 15 ; 22,5 ; 30 \%)$ de farinha de varredura de mandioca na dieta de frangos de corte de 1 a 42 dias de idade não observaram interferência nos rendimentos de carcaça, peito, coxa e sobrecoxa, asa e dorso com pescoço. Pimentel et al. (2007) substituíram $50 \%$ do milho por sorgo e não verificaram significância sobre características de carcaça de frangos de corte aos 42 dias de idade.

Para alometria do coração, fígado, proventrículo e moela e de biometria do duodeno, jejuno, íleo, cólon-reto e cecos das aves abatidas aos 47 dias de idade, os resultados revelaram ausência de significância para a interação FBD e CE e para os efeitos principais da FBD ou do CE. Para os dados alométricos da moela e do coração observou-se resposta polinomial linear decrescente e quadrática com ponto de máximo de 17,05\%, respectivamente (Tabela 7 ). 
NUNES, J.K. et al. Características de carcaça e do trato digestório de frangos alimentados com batata doce e enzimas. PUBVET, Londrina, V. 7, N. 11, Ed. 234, Art. 1546, 2013.

Tabela 7. Resultados das análises de variação das variáveis referentes à alometria de órgãos e biometria intestinal dos frangos de corte, aos 47 dias de idade, e equações polinomiais ajustadas para expressar as respostas aos níveis de FBD

\begin{tabular}{|c|c|c|c|c|c|c|c|c|c|}
\hline \multirow[b]{2}{*}{ FBD } & \multicolumn{9}{|c|}{ Característica $^{1}$} \\
\hline & Fig & Cor & Pro & Moe & Duo & Jej & Íleo & Colret & $\mathrm{Cec}$ \\
\hline 0 & 60 & 18 & 9 & 47 & 26 & 104 & 21 & 8 & 19 \\
\hline 20 & 52 & 18 & 10 & 42 & 27 & 116 & 21 & 8 & 18 \\
\hline 40 & 53 & 19 & 10 & 38 & 24 & 104 & 20 & 8 & 18 \\
\hline $\mathrm{P}^{2}$ & 0,1021 & 0,9869 & 0,5002 & 0,0647 & 0,4671 & 0,1832 & 0,7734 & 0,6143 & 0,9053 \\
\hline
\end{tabular}

\begin{tabular}{|c|c|c|c|c|c|c|c|c|c|}
\hline 0 & 55 & 19 & 10 & 40 & 26 & 107 & 21 & 8 & 18 \\
\hline 200 & 55 & 18 & 10 & 45 & 26 & 109 & 20 & 8 & 19 \\
\hline$P^{3}$ & 0,9794 & 0,9844 & 0,6451 & 0,1388 & 0,8883 & 0,7922 & 0,6136 & 0,5989 & 0,6456 \\
\hline
\end{tabular}

FBD - CE

\begin{tabular}{|c|c|c|c|c|c|c|c|c|c|}
\hline $0-0$ & 57 & 19 & 9 & 45 & 26 & 101 & 21 & 8 & 19 \\
\hline $20-0$ & 49 & 16 & 11 & 38 & 26 & 115 & 22 & 8 & 18 \\
\hline $40-0$ & 59 & 22 & 10 & 36 & 26 & 106 & 20 & 8 & 17 \\
\hline $0-200$ & 62 & 18 & 10 & 50 & 25 & 107 & 21 & 8 & 19 \\
\hline $20-200$ & 54 & 21 & 10 & 45 & 28 & 118 & 20 & 9 & 19 \\
\hline $40-200$ & 48 & 16 & 10 & 40 & 23 & 102 & 20 & 8 & 19 \\
\hline $\mathrm{P}^{4}$ & 0,1132 & 0,0983 & 0,7898 & 0,8487 & 0,5529 & 0,7646 & 0,7652 & 0,3289 & 0,8393 \\
\hline $\mathrm{CV}(\%)^{5}$ & 11,49 & 18,44 & 16,34 & 13,21 & 14,49 & 11,40 & 11,34 & 11,60 & 17,01 \\
\hline
\end{tabular}

$\begin{array}{rrrr}\mathrm{CV}(\%)^{5} & 11,49 & 18,44 & 16,34 \\ & & \text { Cte }\end{array}$

$\begin{array}{lll} & \text { Cte } & \\ \text { Curva } & \text { Pro }=9,83\end{array}$

\begin{tabular}{lccccccc} 
Curva & Fig $=54,47$ & Quad. $^{6}$ & & Lin. $^{7}$ & Duo $=25,64$ & Jej $=117,97$ & Íleo $=20,55$ \\
$\mathrm{R}^{28}$ & 0 & 0,87 & 0 & 0,99 & 0 & 0 & Colret $=8,12$ \\
\hline
\end{tabular}

Lin. 7 Cte

Cte Cte

Cte

Cte

${ }^{1}$ Fig: peso do fígado (g), Cor: peso do coração (g), Pro: peso do proventrículo (g), Moe: peso da moela (g), Duo: comprimento do doudeno

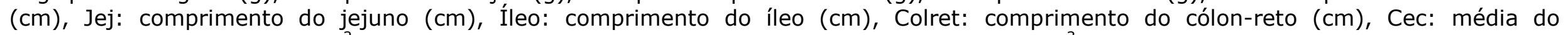
comprimento dos cecos $(\mathrm{cm})$. ${ }^{2}$ Probabilidade de declarar significativo efeito da FBD inexistente. ${ }^{3}$ Probabilidade de declarar significativo efeito do CE inexistente. ${ }^{4}$ Probabilidade de declarar significativo efeito da interação FBD e CE inexistente. ${ }^{5}$ CV (\%): Coeficiente de variação.

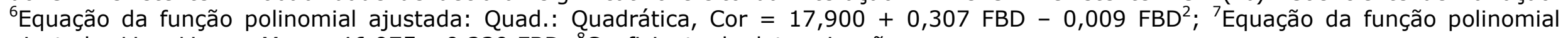
ajustada: Lin.: Linear, Moe $=46,975-0,230$ FBD. ${ }^{8}$ Coeficiente de determinação. 
NUNES, J.K. et al. Características de carcaça e do trato digestório de frangos alimentados com batata doce e enzimas. PUBVET, Londrina, V. 7, N. 11, Ed. 234, Art. 1546, 2013.

Contrariando o que foi observado, Campello et al. (2009) ao substituir milho nos níveis de 0,13, 36 e 53\% por farinha de raízes de mandioca, na dieta de frangos de corte tipo caipira, não observaram efeito significativo desses percentuais sobre os pesos do coração e da moela das aves com 84 dias de idade.

\section{CONCLUSÃo}

A substituição do milho por farinha de batata doce, com ou sem suplementação do complexo enzimático, não foi efetiva sobre as características de carcaça, alometria de órgãos e biometria intestinal.

\section{REFERÊNCIAS}

BONATO, E.L.; ZANELA, I.; SANTOS, R. dos; GASPARINI, S.P.; MAGON, L.; ROSA, A.P.; BRITTES, L.P. Uso de enzimas em dietas contendo níveis crescentes de farelo de arroz integral para frangos de corte. Ciência Rural, v.34, n.2, p.511-516, 2004.

BRITO, M.S. de; OLIVEIRA, C.F.S. de; SILVA, T.R.G. da; LIMA, R.B. de; MORAIS, S.N.; SILVA, J.H.V. da. Polissacarídeos não amiláceos na nutrição de monogástricos. Acta Veterinaria Brasilica, v.2, n.4, p.111-117, 2008.

BRUM JR., B.; ZANELLA, I.; TOLEDO, G.S.P. de; XAVIER, E.G.; VIEIRA, T.A.; GONÇALVES, E.C.; BRUM, H.; OLIVEIRA, J.L.S. de. Dietas para frangos de corte contendo quirera de arroz. Ciência Rural, v.37, n.5, p.1423-1429, 2007.

CAMPELLO, C.C.; SANTOS, M.S.V. do; LEITE, A.G.A.; ROLIM, B.N.; CARDOSO, W.M.; SOUZA, F.M. Características de carcaça de frangos tipo caipira alimentados com dietas contendo farinha de raízes de mandioca. Ciência Animal Brasileira, v.10, n.4, p.10211028, 2009.

COSTA. F.G.P.; CLEMENTINO, R.H.; JÁCOME, I.M.T.D.; NASCIMENTO, G.A.J. do; PEREIRA, W.E. Utilização de um complexo multienzimático em dietas de frangos de corte. Ciência Animal Brasileira, v.5. n.2. p.63-71, 2004.

FREITAS, C.R.G. de; LUDKE, M.C.M.M.; LUDKE, J.V.; RABELLO, C.B.V.; NASCIMENTO, G.R. do; BARBOSA, E.N.R. Inclusão da farinha de varredura de mandioca em rações de frangos de corte. Acta Scientiarum. Animal Sciences, v.30, n.2, p.155-163, 2008.

GARCIA, R.G., MENDES A.A., COSTA, C., PAZ, I.C.L.A., TAKAHASHI, S.E., PELÍCIA, K.P., KOMIYAMA, C.M., QUINTEIRO, R.R. Desempenho e qualidade de carne de frangos de corte alimentados com diferentes níveis de sorgo em substituição ao milho. Arquivo Brasileiro de Medicina Veterinária e Zootecnia, v.57, n.5, p.634-643, 2005. 
PIMENTEL, A.C.S.; DUTRA JR., W.M.; LUDKE, M.C.M.M.; LUDKE, J.V.; RABELLO, C.B.; FREITAS, C.R.G. de. Substituição parcial do milho e farelo de soja por sorgo e farelo de caroço de algodão extrusado em rações de frangos de corte. Acta Scientiarum. Animal Sciences, v.29, n.2, p.135-141, 2007.

ROCHA, V.R.R.A.; DUTRA JR., W.M.; RABELLO, R.C.; RAMALHO, R.P.; LUDKE, M.C.M.M.; SILVA, E.C. da. Substituição total do milho por sorgo e óleo de abatedouro avícola em dietas para frangos de corte. Revista Brasileira de Zootecnia, v.37, n.1, p.95-102, 2008.

ROSTAGNO, H.S; ALBINO L.F.T.; DONZELE, J.L.; GOMES P.C.; OLIVEIRA R.F. de; LOPES D.C.; FERREIRA, A.S.; BARRETO, S.L.T. Tabelas Brasileiras para Aves e Suínos Composição de Alimentos e Exigências Nutricionais. 2. ed. Viçosa: UFV, Departamento de Zootecnia. 2005. 186p.

SANTOS, M.S.V. dos; ESPÍNDOLA, G.B.; FUENTES, M.F.F.; FREITAS, E.R.; CARVALHO, L.E. de. Utilização de complexo enzimático em dietas à base de sorgo-soja para frangos de corte. Revista Brasileira de Zootecnia, v.35, n.3, p.811-817, 2006.

TAKAHASHI, S. E.; MENDES, A. A.; SALDANHA, E. S. P. B.; PIZZOLANTE, C. C.; PELÍCiA, K.; GARCIA, R. G.; PAZ, I. C. L. A.; QUINTEIRO, R. R. Efeito do sistema de criação sobre o desempenho e rendimento de carcaça de frangos de corte tipo colonial. Arquivo Brasileiro de Medicina Veterinária e Zootecnia, v.58, n.4, p.624-632, 2006.

VIEIRA, A.R.; RABELLO, C. B.; LUDKE, M.C.M.; JÚNIOR, W.M.D.; TORRES, D.M.; LOPES, J.B. Efeito de diferentes níveis de inclusão de farelo de arroz em dietas suplementadas com fitase para frangos de corte. Acta Scientiarium. Animal Sciences, v.29, n.3, p.267-275, 2007. 